University of Nebraska - Lincoln

DigitalCommons@University of Nebraska - Lincoln

Food and Drug Administration Papers

U.S. Department of Health and Human Services

2020

\title{
An evaluation of the USDA's policy to reduce listeria illnesses in ready-to-eat meat and poultry products
}

Travis Minor

Center for Food Safety and Applied Nutrition

Matt Parrett

Johns Hopkins University, Washington

Follow this and additional works at: https://digitalcommons.unl.edu/usfda

Part of the Dietetics and Clinical Nutrition Commons, Health and Medical Administration Commons, Health Services Administration Commons, Pharmaceutical Preparations Commons, and the Pharmacy Administration, Policy and Regulation Commons

Minor, Travis and Parrett, Matt, "An evaluation of the USDA's policy to reduce listeria illnesses in ready-to-eat meat and poultry products" (2020). Food and Drug Administration Papers. 45. https://digitalcommons.unl.edu/usfda/45

This Article is brought to you for free and open access by the U.S. Department of Health and Human Services at DigitalCommons@University of Nebraska - Lincoln. It has been accepted for inclusion in Food and Drug Administration Papers by an authorized administrator of DigitalCommons@University of Nebraska - Lincoln. 


\section{An evaluation of the USDA's policy to reduce listeria illnesses in ready-to-eat meat and poultry products}

\section{Travis Minor $^{1}$ | Matt Parrett ${ }^{2}$}

${ }^{1}$ Food and Drug Administration, Center for Food Safety and Applied Nutrition, College Park, Maryland

${ }^{2}$ Advanced Academic Programs, Johns Hopkins University, Washington, District of Columbia

\section{Correspondence}

Matt Parrett, Advanced Academic Programs, Johns Hopkins University, 1717 Massachusetts Avenue NW, Washington, DC 20036.

Email: mbparrett@gmail.com

\begin{abstract}
Using 1998-2008 data collected by the Centers for Disease Control and Prevention on foodborne illnesses and outbreaks, we examine the economic impact of the United States Department of Agriculture's proposed and final rules to reduce the incidence of Listeria monocytogenes $(\mathrm{Lm})$ in ready-toeat meat and poultry products. Using a difference-indifferences approach, we find that these rules together reduced meat-related $L m$ illnesses by about 60 per year, which we attribute to reductions in both the number and average size of meat-related $\mathrm{Lm}$ outbreaks. We then monetize this illness reduction using an underreporting and underdiagnosis multiplier of 2.3 and an estimate of the mean cost of a Lm illness of $\$ 1.5$ million and find that these rules generated about $\$ 208$ million per year in cost savings, which compares favorably to the rules' estimated annual cost of roughly $\$ 22$ million. [EconLit citations: I18, Q18].

KEYWORDS

foodborne illness, Listeria monocytogenes, meat, poultry, regulation
\end{abstract}




\section{1 | INTRODUCTION}

In the wake of a 1998 outbreak of Listeria monocytogenes $(\mathrm{Lm})^{1}$ involving hot dogs and deli meats and causing 101 illnesses, 15 adult deaths, and six stillbirths or miscarriages, the United States Department of Agriculture (USDA) published a proposed rule in February 2001 titled "Performance Standards for the Production of Processed Meat and Poultry Products" (United States Department of Agriculture, 2001). The rule, hereafter referred to in its entirety as the Proposed Standards and Lm Rule, proposed that all ready-toeat meat and poultry products, as well as all partially heat-treated meat and poultry products, meet various food safety standards. The lethality and stabilization standards, respectively, established levels of pathogen reduction and limits on pathogen growth that establishments covered by this rule would need to achieve. The handling standard would require that covered establishments maintain these levels of pathogen reduction and growth in their products under normal handling conditions and until their products reach the consumer. This rule also proposed to eliminate regulations mandating that ready-to-eat and not-ready-to-eat pork and products containing pork, be treated to destroy Trichinella spiralis. Lastly, this rule proposed testing requirements aimed at reducing the occurrence of $L m$ in ready-to-eat meat and poultry products. More specifically, this piece of the proposed rule, hereafter referred to as the Proposed Lm Rule, would require that establishments that produce ready-to-eat meat and poultry products test food contact surfaces for $\mathrm{Lm}$ following lethality treatment but before final product packaging to verify that their Sanitation Standard Operating Procedures (Sanitation SOPs) are preventing direct product contamination by $\mathrm{Lm}$ after the lethality treatment. If a food contact surface is found to test positive for $\mathrm{Lm}$, then the establishment would be required to take corrective actions. ${ }^{2}$

In June 2003, in the wake of a 2002 outbreak of $\mathbf{~} m$ involving turkey deli meat and causing 29 illnesses, four deaths, and three miscarriages or stillbirths, combined with recent recalls of meat and poultry products adulterated by $L m$, the USDA issued an interim final rule ${ }^{3}$ (United States Department of Agriculture, 2003). This rule, which became effective in October 2003 and is referred to hereafter as the Final $\mathrm{Lm}$ Rule, requires that establishments that produce ready-to-eat meat and poultry products that are exposed to the environment following lethality treatment and that support the growth of $L m$ have in their HACCP plans or in their Sanitation SOPs or other programs controls that prevent product adulteration by $\mathrm{Lm}$.

In this paper, we test using a difference-in-differences approach whether the Proposed and Final Lm Rules described above decreased the number of meat-related $\mathrm{Lm}$ illnesses. To do this, we use novel 1998-2008 data on foodborne illnesses and outbreaks by commodity and pathogen collected by the Centers for Disease Control and Prevention (CDC) and compiled by Painter et al. (2013). For purposes of this

\footnotetext{
${ }^{1}$ The infection caused by eating food contaminated with the pathogen Lm is known as listeriosis (Centers for Disease Control and Prevention, 2016). The symptoms of listeriosis are fever and diarrhea (Centers for Disease Control and Prevention, 2017). Invasive listeriosis, a much more severe form of listeriosis in which the pathogen $L m$ has spread beyond the gut, causes, in pregnant women, fever, fatigue, and muscle aches and can lead to miscarriage, stillbirth, premature delivery, or life-threatening infection of the newborn (Centers for Disease Control and Prevention, 2017). In people other than pregnant women, symptoms of invasive listeriosis can, in addition to fever and muscle aches, include headache, stiff neck, confusion, loss of balance, and convulsions (Centers for Disease Control and Prevention, 2017). Listeriosis is most likely to sicken pregnant women and their newborns, older adults, and individuals with weakened immune systems (Centers for Disease Control and Prevention, 2016).

${ }^{2}$ Establishments who in their Hazard Analysis and Critical Control Point (HACCP) plan have identified Lm as a hazard reasonably likely to occur, and have established critical control points (CCPs) validated to eliminate $\mathrm{Lm}$ from their products, would be exempt from this testing requirement (based on data reported in the Proposed Standards and Lm Rule, about a quarter of the industry was exempt at the time from this testing requirement for this reason). HACCP is a preventive system of hazard control.

${ }^{3}$ The typical first stage of the rulemaking process is the Advanced Notice of Proposed Rulemaking (ANPRM). An ANPRM is essentially an announcement to the public that the agency authoring the ANPRM is interested in making a rule. There is usually a comment period associated with an ANPRM, whereby the public is given the opportunity to send comments to the agency authoring the ANPRM about the rule in question. The typical second stage of the rulemaking process is the Proposed Rule. A Proposed Rule clearly defines and makes a case for the rule in question. Like with an ANPRM, there is usually a comment period associated with a Proposed Rule. The typical third stage of the rulemaking process is the Final Rule. An agency might instead issue an Interim Final Rule. Final Rules and Interim Final Rules carry legal authority. In contrast, the public is not legally compelled to adhere to anything promulgated in either an ANPRM or a Proposed Rule. The difference between an Interim Final Rule and a Final Rule is that there is usually a comment period associated with an Interim Final Rule, after which the Interim Final Rule is normally finalized and becomes a Final Rule.
} 
analysis, and consistent with the coverage of the Proposed and Final Lm Rules, meat comprises beef, pork, and poultry.

This paper ties most closely to the literature on food safety standards. A number of studies in this literature look at the effect of food safety standards, most notably HACCP, on the microbiological quality of foods, finding that they are effective in improving the microbiological quality of the food or foods studied (e.g., Amoa-Awua et al., 2007; Cenci-Goga et al., 2005; Hong, Todd, \& Bahk, 2008; Nada, Ilija, Igor, Jelena, \& Ruzica, 2012; Soriano, Rico, Molto, \& Manes, 2002; Wang et al., 2010). A smaller number of studies centers on health effects. We know of just two studies, Asfaw, Mithofer, and Waibel (2010) and Okello and Swinton (2010), which examine the effect of food safety standards on the health of the producer and two studies, Vojdani, Beuchat, and Tauxe (2008) and Minor and Parrett (2017), which look at the effect of food safety standards on the health of the consumer. The focus of Vojdani et al. (2008) and Minor and Parrett (2017) is on the effect of a Food and Drug Administration (FDA) final rule published in January 2001 aimed at reducing the number of foodborne illnesses associated with juice products. These studies, respectively, find that the January 2001 rule reduced juice-related outbreaks and illnesses. Our paper fits closest to this latter, consumer health strand of the food safety standards literature and, to the best of our knowledge, is the first to examine the impact of the Proposed and Final Lm Rules on the number of meatrelated $L m$ illnesses.

Our work is important from a policy standpoint because it informs the economic impact analysis of the Final $\mathrm{Lm}$ Rule, referred to as the Final Regulatory Impact Analysis (FRIA). Such an analysis consists of estimates of a rule's costs and benefits and by Presidential Executive Order is a required part of the regulation promulgation process. Using our estimates of the combined effect of the Proposed and Final Lm Rules on the number of meat-related $\mathrm{Lm}$ illnesses, we reevaluate the benefits of the Final $L m$ Rule that were estimated by the USDA in the Final $L m$ Rule FRIA. We consider the combined impact of the Proposed and Final $L m$ Rules in our reevaluation because existing evidence suggests that the public responds to proposed rules (Minor \& Parrett, 2016; Strom, 2012; Thrasher, 2013), presumably in anticipation that such rules will eventually be finalized.

The layout of this paper is as follows. Section 2 provides a description of the data used in our analysis. Section 3 discusses our estimation methodology. Section 4 presents our results and Section 5 discusses those results. Section 6 concludes.

\section{2 | DATA DESCRIPTION}

The data used in this analysis are from outbreak reports collected by the CDC from 1998 to $2008 .{ }^{4}$ The data originate from reports by state, local, and territorial public health agencies to the CDC's Foodborne Disease Outbreak Surveillance System (FDOSS) using the National Outbreak Reporting System (NORS). Information such as the date and location of the outbreak, the number of people who became ill and their symptoms, the food or foods implicated in the outbreak, where the food was prepared and eaten, and the pathogen implicated in the outbreak are all collected in FDOSS. Such data are eventually made available to the public through the CDC's Foodborne Outbreak Online Database (FOOD). Although reporting is voluntary, it is likely that the most serious foodborne illness incidents (those which are felt widely in the population) are catalogued by these data.

There were 13,352 outbreaks and 271,974 illnesses reported to the CDC between 1998 and 2008 (Painter et al., 2013). ${ }^{5}$ However, given the raw nature of these data, cleaning and compiling them for use is no small feat.

\footnotetext{
${ }^{4} \mathrm{An}$ outbreak is defined by the CDC as two or more people experiencing a similar illness from eating or drinking the same food.

${ }^{5}$ According to the CDC's FOOD disclaimer, because reporting agencies can modify their reports at any time, even months or years after an outbreak, FOOD results are subject to change. Hence, the outbreak and illness counts reported in Painter et al. (2013), which are as of October 2010, differ slightly from those which are currently reported in FOOD. For example, as of May 26, 2017, FOOD reveals a total of 13,375 outbreaks and 272,808 illnesses reported to the CDC between 1998 and 2008.
} 
First, because all outbreak investigations do not result in a complete collection of information, there is a substantial amount of missing information among these data. For example, just over half of the 13,352 reported outbreaks are able to implicate a food vehicle (Painter et al., 2013). Second, of those outbreaks that do implicate a food vehicle, it may range from something simple to categorize, such as lettuce or tomatoes, to something more complex, such as lasagna or a hamburger.

Painter et al. (2013) clean and compile the 1998-2008 raw CDC data by distributing all simple and complex food outbreaks for which there is a single implicated pathogen and the ingredients of the contaminated food(s) can be characterized among a standard set of 17 food commodities (product categories). The product categories are leafy vegetables, dairy, fruits/nuts, poultry, vine/stalk vegetables, beef, eggs, pork, grains/beans, root vegetables, mollusk, fish, oils/sugars, crustacean, sprout vegetables, game, and fungi vegetables.

The publicly available Painter et al. (2013) data are such that for a simple food outbreak involving a particular pathogen, illnesses are allocated to the single implicated commodity. For example, if an outbreak of Pathogen $X$ involving pulled pork caused nine illnesses, then Painter et al. (2013) would allocate all nine illnesses to the pork product category. For a complex food outbreak involving a particular pathogen, a recipe is applied to the complex food, the result of which is a vector of simple foods that comprise the complex food. Each simple food is then assigned to one of the 17 product categories listed above. IIInesses are allocated evenly across the affected product categories. For example, if an outbreak of Pathogen $Y$ involving hamburgers caused 15 illnesses, a recipe would first be applied to the hamburger, defining a hamburger, say, as consisting of beef (beef product category) and a bun (grains/beans product category). Then, 7.5 illnesses would be allocated to the beef product category and 7.5 illnesses would be allocated to the grains/beans product category.

After excluding outbreaks because of insufficient information, as well as outbreaks involving multiple pathogens, Painter et al. (2013) compile a data set consisting of 4,589 outbreaks (34\% of total outbreaks) and 120,321 illnesses (44\% of total illnesses) that occurred between 1998 and $2008 .^{6,7}$ Using these data, we construct a panel of the 17 mutually exclusive food commodities listed above. This allows us to examine trends in illnesses attributable to each food commodity over the 11-year period. Beginning with the 4,589 individual outbreaks, we aggregate the data by year and food commodity to generate a panel consisting of 187 observations (=11 years $\times 17$ food commodities). Summary statistics for our panel are presented in Table 1 and reveal that approximately $1.8 \mathrm{Lm}$ illnesses occurred annually per product category (looking across just meat products, this figure is a larger $7.8 \mathrm{Lm}$ illnesses per meat product per year).

Figure 1 illustrates annual Lm illnesses associated with meat products which, as stated previously, comprise the poultry, beef, and pork product categories. There was a fairly steep decline in meat-related Lm illnesses after the publication of the Proposed Lm Rule followed by a less sharp and more gradual decline in meat-related $\mathrm{Lm}$ illnesses following the publication of the Final $L m$ Rule. ${ }^{8}$

We created an indicator variable for meat products, as well as for each of the 14 remaining food commodities comprising the data. Table 1 reveals that roughly $18 \%(=33 / 187)$ of the data represent meat products. Because we have a balanced panel of food commodity variables over time (11 observations per food commodity), each of the other product-specific indicator variables, referred to collectively as the "Product Fixed Effects", will account for roughly $6 \%$ of the total observations (=11/187 or $1 / 17)$.

\footnotetext{
${ }^{6}$ Using CDC NORS data and looking across the wider 1998-2017 time period, we found that very few Lm outbreaks involved multiple pathogens-for example, of the 80 outbreaks during this time period that implicated $\mathrm{Lm}$, just two implicated an additional pathogen as well.

${ }^{7}$ Note that between 1998 and 2008 there were 21 outbreaks in which $\mathrm{Lm}$ was the single implicated pathogen and those outbreaks resulted in a total of 336 illnesses.

${ }^{8}$ As stated previously, the Final Lm Rule became effective late in 2003 (October 2003). Hence, for purposes of our analysis, we use 2004 as the effective year.
} 
TABLE 1 Summary statistics

\begin{tabular}{|c|c|c|c|c|c|}
\hline & Variable definition & Mean & $\begin{array}{l}\text { Standard } \\
\text { deviation }\end{array}$ & Minimum & Maximum \\
\hline \multicolumn{6}{|l|}{ Outcomes } \\
\hline Lm illnesses & Number of $L m$ illnesses & 1.80 & 6.97 & 0.00 & 54.00 \\
\hline Lm outbreaks & Number of $L m$ outbreaks & 0.11 & 0.33 & 0.00 & 2.00 \\
\hline $\begin{array}{l}\text { Avg. Lm illness per } \\
\text { outbreak }\end{array}$ & Average $L m$ illnesses per outbreak & 2.12 & 8.42 & 0.00 & 54.00 \\
\hline \multicolumn{6}{|l|}{ Key variables } \\
\hline Final $L m$ rule $\times$ Meat & Interaction term & 0.08 & 0.27 & 0.00 & 1.00 \\
\hline Final $\mathrm{Lm}$ rule & $(0 / 1)=1$ in $2004+$ & 0.45 & 0.50 & 0.00 & 1.00 \\
\hline Meat & $\begin{array}{l}(0 / 1)=1 \text { for beef, chicken, and pork } \\
\text { products }\end{array}$ & 0.18 & 0.38 & 0.00 & 1.00 \\
\hline $\begin{array}{l}\text { Proposed } \mathrm{Lm} \\
\quad \text { rule } \times \text { Meat }\end{array}$ & Interaction term & 0.13 & 0.34 & 0.00 & 1.00 \\
\hline Proposed $\mathrm{Lm}$ rule & $(0 / 1)=1$ in $2001+$ & 0.73 & 0.45 & 0.00 & 1.00 \\
\hline \multicolumn{6}{|l|}{ Price and volume } \\
\hline Consumer price index & $\begin{array}{l}\text { Measure of consumer inflation specific } \\
\text { to commodity }\end{array}$ & 1.33 & 0.97 & 0.38 & 4.13 \\
\hline Producer price index & $\begin{array}{l}\text { Measure of producer inflation specific } \\
\text { to commodity }\end{array}$ & 144.43 & 45.21 & 61.10 & 334.60 \\
\hline $\begin{array}{l}\text { Consumer } \\
\quad \text { expenditures (\$) }\end{array}$ & $\begin{array}{l}\text { Average amount in } \$ \text { consumers spend } \\
\text { on each commodity }\end{array}$ & 214.29 & 103.18 & 32.00 & 507.00 \\
\hline $\begin{array}{l}\text { Food available } \\
\text { (billion/lbs.) }\end{array}$ & $\begin{array}{l}\text { Amount in lbs. of each food commodity } \\
\text { available to each consumer }\end{array}$ & 26.26 & 26.97 & 0.06 & 84.58 \\
\hline $\begin{array}{l}\text { Import volume } \\
\text { (billion/lbs.) }\end{array}$ & $\begin{array}{l}\text { Amount in lbs. of each food commodity } \\
\text { imported into the United States }\end{array}$ & 4.86 & 3.23 & 0.00 & 15.19 \\
\hline Import value (billion/\$) & $\begin{array}{c}\text { Amount in } \$ \text { of each food commodity } \\
\text { imported into the United States }\end{array}$ & 5.70 & 3.75 & 1.13 & 13.91 \\
\hline \multicolumn{6}{|l|}{ Previous rules } \\
\hline Final standards rule & $(0 / 1)=1$ in $1999+$ & 0.91 & 0.29 & 0.00 & 1.00 \\
\hline
\end{tabular}

Notes: $N=187$. Summary statistics for each of the 14 remaining products are identical (Mean $=0.06$, standard deviation $(S D)=0.24)$, and so are not presented. Summary statistics for the year fixed effects are not presented but are identical (Mean $=0.09, S D=0.29$ ). The variable Meat comprises beef, pork, and poultry products.

Too, we created an indicator variable for each pathogen present in the data, which are summarized in Table 2 and referred to collectively as the "Pathogen Controls." Looking at Table 2, it can be seen that approximately $14 \%$ of our 187 food commodity, year observations are associated with $\mathrm{Lm}$.

In addition, we collected data on various price and volume measures, as well as other regulations, which might affect the occurrence or magnitude of an Lm illness. These are summarized in Table 1. The price and volume measures, which vary at both the year and food commodity level, include the consumer price index, the producer price index, and consumer expenditures, all of which are collected annually by the Bureau of Labor Statistics for each food commodity, and food available, import volume, and import value, all of which are collected by the USDA Economic Research Service. There is one related regulation that we know of that occurred during the 1998-2008 time period for which we are able to control. In January 1999, the USDA published a rule titled "Performance Standards for the Production of Certain Meat and Poultry Products" (United States Department of Agriculture, 1999), which we refer to in this paper as the Final Standards Rule. 


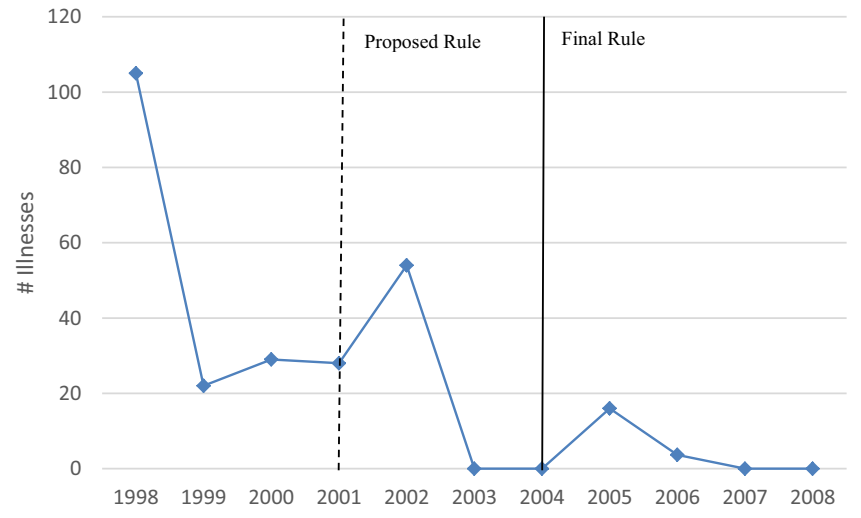

FIGURE 1 Annual meat-related Listeria monocytogenes $(\mathrm{Lm})$ illnesses. Meat comprises beef, pork, and poultry products. "Proposed Rule" refers to the Proposed $L m$ Rule that was published in February 2001. "Final Rule" refers to the Final $L m$ Rule that became effective in October 2003 (for purposes of our analysis, we use 2004 as the effective year) [Color figure can be viewed at wileyonlinelibrary.com]

The scope of this rule, which became effective in March 1999, is similar to the scope of the standards piece of the Proposed Standards and $L m$ Rule, in that this rule mandated lethality, stabilization, and handling food safety performance standards for ready-to-eat and partially heat-treated meat and poultry products. ${ }^{9}$ In addition, the Final Standards Rule required the implementation of a HACCP plan in covered facilities. ${ }^{10}$ However, where the two rules differ is in terms of coverage. The Final Standards Rule covers only certain ready-to-eat and partially heat-treated meat and poultry products, including ready-to-eat roast beef, corned beef, and cooked beef, all fully-cooked ready-to-eat poultry products, and partially-cooked meat patty and poultry products. ${ }^{11}$ In contrast, the standards piece of the Proposed Standards and Lm Rule covers all readyto-eat and partially heat-treated meat and poultry products.

\section{3 | ESTIMATION METHODOLOGY}

We use a difference-in-differences approach to estimate the effect of the Proposed and Final Lm Rules on the number of meat-related $L m$ illnesses. Such an approach is appropriate when evaluating the effect of a natural experiment, where a treatment is applied to one group, the treated group, but not a second group, often noted as the control group. The treatments here are the Proposed and Final Lm Rules and the treated group is meat products which, again, comprise beef, pork, and poultry products. The control group comprises the remaining product categories.

An underlying assumption of difference-in-differences, often referred to as the common trends assumption, is that the treated and control groups were behaving similarly before the treatment. A violation of this assumption with respect to the Proposed $L m$ Rule would be seen if non-meat-related $L m$ illnesses were on a different trend line than meat-related $L m$ illnesses before 2001, the publication date of the Proposed $L m$ Rule. Looking at Figure 2, which illustrates meat- and non-meat-related Lm illnesses over time, it can be seen

\footnotetext{
${ }^{9}$ Note that the standards that comprise both the Final Standards Rule and the standards piece of the Proposed Standards and Lm Rule are processing (e.g., cooking) standards and $\mathrm{Lm}$ is not a major pathogen of concern in the processing environment (United States Department of Agriculture, 2001). In contrast, the Proposed Lm Rule and the Final Lm Rule are aimed at the post-processing (e.g., slicing) environment in which $L m$ is a major pathogen of concern.

${ }^{10}$ HACCP plans were originally introduced into federal regulated meat production in 1996, with the publication of the final rule "Pathogen Reduction: Hazard Analysis and Critical Control Point (HACCP) Systems" (United States Department of Agriculture, 1996). The publication of the Final Standards Rule redefined the timeframe for HACCP implementation.

${ }^{11}$ In addition, the Final Standards Rule and HACCP do not explicitly address contamination from Lm, focusing instead on Escherichia coli and Salmonella.
} 
TABLE 2 Summary statistics for pathogen controls

\begin{tabular}{|c|c|c|c|c|}
\hline Pathogen & Mean & Standard deviation & Minimum & Maximum \\
\hline Anisakis & 0.01 & 0.07 & 0 & 1 \\
\hline Bacillus cereus & 0.74 & 0.44 & 0 & 1 \\
\hline Brucella & 0.02 & 0.15 & 0 & 1 \\
\hline Campylobacter & 0.49 & 0.50 & 0 & 1 \\
\hline Clostridium botulinum & 0.21 & 0.41 & 0 & 1 \\
\hline Clostridium perfringens & 0.78 & 0.42 & 0 & 1 \\
\hline Cryptosporidium & 0.04 & 0.20 & 0 & 1 \\
\hline Cyclospora & 0.13 & 0.34 & 0 & 1 \\
\hline Escherichia coli & 0.65 & 0.48 & 0 & 1 \\
\hline Giardia & 0.09 & 0.28 & 0 & 1 \\
\hline Hepatitis A & 0.26 & 0.44 & 0 & 1 \\
\hline Listeria monocytogenes & 0.14 & 0.35 & 0 & 1 \\
\hline Marine Biotoxins & 0.28 & 0.45 & 0 & 1 \\
\hline Mycotoxins & 0.06 & 0.25 & 0 & 1 \\
\hline Norovirus & 1.00 & 0.00 & 1 & 1 \\
\hline Other Chemicals & 0.58 & 0.50 & 0 & 1 \\
\hline Rotavirus & 0.10 & 0.30 & 0 & 1 \\
\hline Salmonella & 0.93 & 0.26 & 0 & 1 \\
\hline Sapovirus & 0.01 & 0.10 & 0 & 1 \\
\hline Shigella & 0.50 & 0.50 & 0 & 1 \\
\hline Staphylococcus & 0.81 & 0.39 & 0 & 1 \\
\hline Trichinella & 0.06 & 0.25 & 0 & 1 \\
\hline Vibrio & 0.28 & 0.45 & 0 & 1 \\
\hline Yersinia & 0.05 & 0.21 & 0 & 1 \\
\hline
\end{tabular}

Notes: $N=187$. Our dependent variables are Listeria monocytogenes $(L m)$ specific; hence, we exclude the $L m$ pathogen control from our analyses. We exclude the Norovirus pathogen control from our analyses because of perfect collinearity (the pathogen Norovirus is present in each of our 187 year/commodity observations).

that these illnesses were roughly parallel before the publication of the Proposed $L m$ Rule. ${ }^{12}$ Detecting violations of the common trends assumption with respect to the Final $\mathrm{Lm}$ Rule requires a comparison of

\footnotetext{
${ }^{12} \mathrm{As}$ a confirming check of the common trends assumption, we regressed the number of $\mathrm{Lm}$ Illnesses on an indicator variable for meat products (Meat), a vector of year indicator variables (Y1998, Y1999, Y2000, Y2001), and a vector of variables that interact the meat indicator variable and each year indicator variable, respectively, and obtained results consistent with the visual evidence presented in Figure 2. More specifically, the coefficient on Meat $\times$ Y1999 in a regression model with Y1998 suppressed is statistically significant ( $p<.001$, two-tailed $t$ test), suggesting that the marginal effect of Y1999 relative to Y1998 on the number of $L m$ Illnesses is different for meat and non-meat products. However, the coefficients on Meat $\times$ Y2000 in a regression model with Y1999 suppressed ( $p=.724$, two-tailed $t$ test) and on Meat $\times$ Y2001 in a regression model with Y2000 suppressed ( $p=.900$, two-tailed $t$ test) are not statistically significant, suggesting that the marginal effects of $Y 2000$ relative to $Y 1999$, and of $Y 2001$ relative to $Y 2000$, on the number of $L m$ Illnesses is the same for meat and non-meat products. Note that dropping the 1998 observations from our analysis, the results of which are presented in Appendix Table A-1, produces a combined effect of the Proposed and Final Lm Rules on the number of meat-related $\mathrm{Lm}$ illnesses, outbreaks, and average illnesses that is in most cases smaller in magnitude, but does not otherwise alter any of our conclusions.
} 


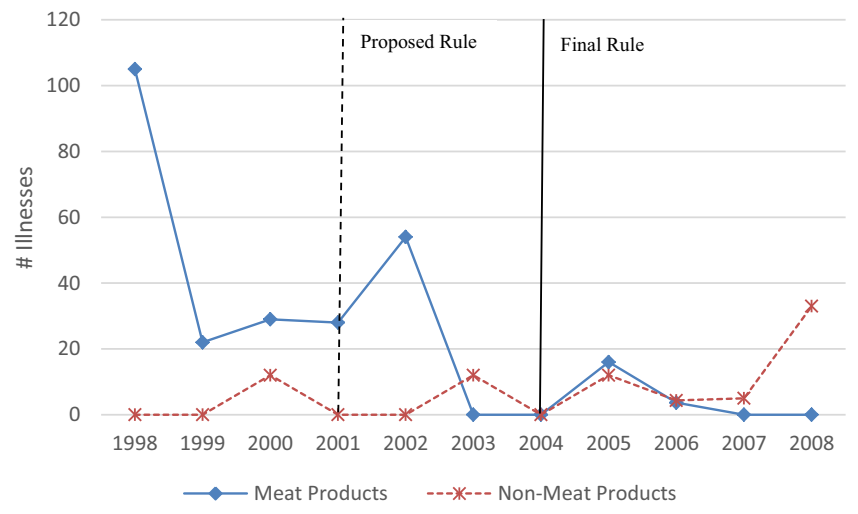

FIGURE 2 Annual meat- and nonmeat-related Listeria monocytogenes $(\mathrm{Lm})$ illnesses. Meat comprises beef, pork, and poultry products. "Proposed Rule" refers to the Proposed $L m$ Rule that was published in February 2001. "Final Rule" refers to the Final $L m$ Rule that became effective in October 2003 (for purposes of our analysis we use 2004 as the effective year) [Color figure can be viewed at wileyonlinelibrary.com]

meat- and non-meat-related $L m$ illnesses before 2004, the year in which the rule became effective. ${ }^{13}$ We begin with a comparison of meat- and non-meat-related Lm illnesses before 2001 which, as stated above, reveals that these illnesses were roughly parallel. Such a comparison after 2001 is not meaningful because we expect meat- and non-meat-related $L m$ illnesses to be on different trend lines following the publication of the Proposed $L m$ Rule because, in turn, and as stated earlier, existing evidence suggests that the public responds to proposed rules (Minor \& Parrett, 2016; Strom, 2012; Thrasher, 2013), presumably in anticipation that such rules will eventually be finalized.

Given the above setup, we estimate various specifications of the following econometric model using Ordinary Least Squares:

$$
\begin{aligned}
Y_{i, t}= & \alpha_{0}+\alpha_{1} \text { Proposed Lm Rule }_{t} \times \text { Meat }_{i}+\alpha_{2} \text { Final Lm Rule } \text { f }_{t} \times \text { Meat }_{i}+\alpha_{3} \text { Proposed Lm Rule }_{t} \\
& +\alpha_{4} \text { Final Lm Rule } \text { R }_{t}+\alpha_{5} \text { Meat }_{i}+\alpha_{6} X_{i, t}+\alpha_{7} \text { Final Standards Rule } e_{t}+\alpha_{8} P_{i}+\alpha_{9} Z_{t}+\varepsilon_{i, t},
\end{aligned}
$$

where $Y_{i, t}$ is the total number of $L m$ illnesses by product-year, $\alpha_{0}$ is the intercept term, Proposed $L m$ Rule $e_{t}$ is an indicator variable for the Proposed $\mathrm{Lm}$ Rule and is equal to one in 2001 and beyond and zero otherwise, Final $\mathrm{Lm}$ Rule $_{t}$ is an indicator variable for the Final $L m$ Rule and is equal to one in 2004 and beyond and zero otherwise, and Meat $t_{i}$ is an indicator variable for meat products which, again, comprise beef, pork, and poultry products. Note that the scope of the Proposed and Final $L m$ Rules is just ready-to-eat meat and poultry products, but the data we use in this analysis capture all meat and poultry products (all beef, pork, and poultry products) and are such that we are unable to separate out ready-to-eat meat and poultry products from all meat and poultry products. Hence our estimates of the effects of the Proposed and Final Lm Rules potentially capture the effects of these rules on the number of $L m$ illnesses associated not just with ready-to-eat meat and poultry products, but other meat and poultry products, too (spillover effects). ${ }^{14}$

$X_{i, t}$ is a vector of price, volume, and pathogen controls. The price controls, which include the consumer price index, the producer price index, and consumer expenditures, capture any variability in $L m$ illnesses that may occur as a result of the individual prices that consumers are faced with when purchasing each product. For example, a relative increase in meat product prices in a particular year would, all else equal, render such products less

\footnotetext{
${ }^{13}$ As stated previously, the Final Lm Rule became effective late in 2003 (October 2003), so we use 2004 as the effective year.

${ }^{14}$ For example, it is possible that manufacturers who produce both ready-to-eat meat and poultry products, as well as other meat and poultry products, may apply more rigorous food safety standards to all of their product lines, not only the ready-to-eat meat lines, as required. The implication of this is that the benefits of controlling for the presence of $L m$ on food contact surfaces meant for ready-to-eat meat and poultry products could extend to other meat and poultry products as well. It is also possible that no spillover effects exist, and our results only capture the effect on ready-to-eat products, but, from the data, we are unable to say for certain.
} 
desirable to consumers and intermediate good producers, the result of which would be a decrease in the expected number of meat-related Lm illnesses in that year. The volume controls, which include food available, import volume, and import value, capture any change in Lm illnesses that may occur as a result of the volume of food supplied to the average American consumer. For example, a higher volume of meat products supplied to the average American consumer in a given year would increase the expected number of meat-related Lm illnesses in that year. The pathogen controls, the construction of which was discussed in full in Section 2, are included to control for any pathogen-specific heterogeneity that might impact our estimate of the effect of the Proposed and Final Lm Rules on the number of meat-related $L m$ illnesses.

The variable Final Standards Rule is an indicator variable for the Final Standards Rule and is equal to one in 1999 and beyond and zero otherwise. The Final Standards Rule was discussed in full in Section 2.

The product-fixed effects, $P_{i}$, were discussed in full in Section 2 . They are included to control for any timeconstant product-specific heterogeneity that might impact our estimate of the effect of the Proposed and Final $L m$ Rules on the number of meat-related $L m$ illnesses. The year-fixed effects, $Z_{t}$, are included to control for any yearspecific heterogeneity constant over commodities that might impact our estimate of the effect of the Proposed and Final $L m$ Rules on the number of meat-related $L m$ illnesses.

Finally, $\varepsilon_{i, t}$ is a random error term. Our primary interest is in $\alpha_{1}$ and $\alpha_{2}$, the difference-in-differences estimates, respectively, of the effect of the Proposed and Final $L m$ Rules on the number of meat-related $L m$ illnesses. Note that given the scope of the Proposed Standards and Lm Rule, it is possible that in addition to capturing the effect of the Proposed $L m$ Rule, $\alpha_{1}$ might also pick up the effect of the proposed lethality, stabilization, and handling food safety

TABLE 3 The effect of the Proposed and Final Lm Rules on meat-related Lm illnesses

\begin{tabular}{|c|c|c|c|c|}
\hline & Model 1 & Model 2 & Model 3 & Model 4 \\
\hline \multirow[t]{2}{*}{ Final Lm Rule $\times$ Meat } & $-7.725^{* * *}$ & $-7.740^{* * *}$ & $-7.944^{* * *}$ & $-7.380^{* * *}$ \\
\hline & $(0.403)$ & $(1.312)$ & $(1.272)$ & $(2.084)$ \\
\hline \multirow[t]{2}{*}{ Final Lm Rule } & -0.322 & 0.072 & -2.040 & -2.861 \\
\hline & $(0.535)$ & $(0.740)$ & $(2.356)$ & (3.868) \\
\hline \multirow[t]{2}{*}{ Meat } & $16.245^{* * *}$ & $15.783^{* * *}$ & 3.499 & -11.592 \\
\hline & $(1.014)$ & $(1.667)$ & $(6.447)$ & $(12.511)$ \\
\hline \multirow[t]{2}{*}{ Proposed Lm Rule $\times$ Meat } & $-9.404^{* * *}$ & $-9.154^{* * *}$ & $-11.712^{* * *}$ & $-12.454^{* * *}$ \\
\hline & $(0.776)$ & $(1.528)$ & $(2.630)$ & (3.722) \\
\hline \multirow[t]{2}{*}{ Proposed Lm Rule } & 1.100 & -0.611 & 1.367 & 2.144 \\
\hline & (1.329) & $(1.326)$ & (1.539) & (3.013) \\
\hline Observations & 187 & 187 & 187 & 187 \\
\hline$R^{2}$ & 0.389 & 0.435 & 0.486 & 0.549 \\
\hline Price, volume, and previous rules & $x$ & $x$ & $x$ & $x$ \\
\hline Pathogen controls & & $x$ & & $x$ \\
\hline Product fixed effects & & & $x$ & $x$ \\
\hline Year fixed effects & & & $x$ & $x$ \\
\hline
\end{tabular}

Notes: The dependent variable is the total number of $L m$ illnesses. The variable Meat comprises beef, pork, and poultry products. In Models 1 and 2, the coefficient on Meat is interpreted relative to non-meat products, and in Models 3 and 4 the coefficient on Meat is interpreted relative to the suppressed product category fish, hence the discrepancy in the statistical significance of the coefficients on Meat between the models. Robust standard errors that are clustered at the product level (meat products are treated as a single cluster) are shown in parentheses. Full results are available from the authors upon request.

***, ${ }^{* *}$, and ${ }^{*}$ denote $1 \%, 5 \%$, and $10 \%$ significance levels, respectively (two-tailed $t$ tests). 
performance standards on the number of meat-related $L m$ illnesses. However, the proposed lethality, stabilization, and handling food safety performance standards are processing (e.g., cooking) standards and $L \mathrm{~m}$ is not a major pathogen of concern in the processing environment (United States Department of Agriculture, 2001). Hence, such standards are unlikely to exert much, if any, of an effect on Lm illnesses. In contrast, the Proposed $L m$ Rule is aimed at the post-processing (e.g., slicing) environment, an environment in which $\mathrm{Lm}$ is a major pathogen of concern (United States Department of Agriculture, 2001).

\section{\begin{tabular}{l|l}
4 & RESULTS
\end{tabular}}

Table 3 presents our difference-in-differences estimates of the effect of the Proposed and Final $L m$ Rules on the number of $L m$ illnesses associated with meat products. Model 1, which includes just the price, volume, and previous rules controls, reveals that the Proposed and Final $L m$ Rules reduced the number of meat-related $L m$ illnesses by approximately 9.4 and 7.7 illnesses per meat product per year, or by about $28.2(=9.4 \times 3)$ and $23.1(=7.7 \times 3)$ illnesses per year, respectively. Model 2 adds to Model 1 pathogen controls and reveals very similar results. Model 3, which adds to Model 1 product and year fixed effects, reveals that the Proposed and Final $L m$ Rules reduced the respective number of meat-related $L m$ illnesses by roughly $35.1(=11.7 \times 3)$ and $23.7(=7.9 \times 3)$ Lm illnesses annually. Finally, Model 4 , which includes the full set of controls, reveals that the Proposed and Final $L m$ Rules reduced the number of $L m$ illnesses associated with meat products, respectively, by about $37.5(=12.5 \times 3)$ and $22.2(=7.4 \times 3)$ illnesses per year.

We also consider the effects of the Proposed and Final $L m$ Rules on the number of meat-related $L m$ outbreaks and on the average size of a meat-related $L m$ outbreak, which are illustrated in Table 4. Focusing first on outbreaks, looking across Models 1 through 4 reveals that the Proposed $L m$ Rule reduced the number of meat-related $L m$ outbreaks by between $1.5(=0.5 \times 3)$ and $1.8(=0.6 \times 3)$ outbreaks per year and that the Final $L m$ Rule reduced the number of $L m$ outbreaks associated with meat products by between 0 and $0.6(=0.2 \times 3)$ outbreaks per year. Looking next at outbreak size, looking across Models 1 through 4 shows that the Proposed $\mathrm{Lm}$ Rule reduced the average size of a meat-related $\mathrm{Lm}$ outbreak by between $42.6(=14.2 \times 3)$ and $51.0(=17.0 \times 3)$ illnesses and that the Final $\mathrm{Lm}$ Rule reduced the average size of a meat-related $\mathrm{Lm}$ outbreak by between $20.4(=6.8 \times 3)$ and $25.2(=8.4 \times 3)$ illnesses.

We note that the generally statistically insignificant coefficients on Proposed Lm Rule and Final Lm Rule which, respectively, capture the effects of these rules on the number of non-meat-related $L m$ illnesses, non-meat-related $L m$ outbreaks, and average size of a non-meat-related $L m$ outbreak, serve as falsification tests and lend credence to our control group. As a second falsification test, we repeated the analyses in Tables 3 and 4 using non- $L m$ outcomes as the dependent variable. Focusing on the Model 3 and Model 4 results (the full model results) reveals that the rules did not, in addition to reducing the number of meat-related $L m$ illnesses, the number of meat-related $L m$ outbreaks, and the average size of a meat-related $L m$ outbreak, also reduce the number of meat-related non- $L m$ illnesses, the number of meat-related non-Lm outbreaks, and the average size of a meat-related non- $L m$ outbreak, hence lending credence to our results in Tables 3 and $4 .{ }^{15}$

\section{5 | DISCUSSION}

We find evidence that the Proposed and Final $L m$ Rules together reduced the number of $L m$ illnesses associated with meat products. In addition, we find that this drop in meat-related $L m$ illnesses is attributable to both reducing

\footnotetext{
${ }^{15}$ It is also common in difference-in-differences analyses to, as a robustness check, include specifications which include cross-section specific time trends. However, Angrist and Pischke (2009) suggest that such an approach is likely to be more robust and convincing when the pretreatment data establish a clear trend that can be extrapolated into the posttreatment period. In our case, however, it can be seen by looking at Figure 2 that the pretreatment data do not establish a clear trend that can be extrapolated into the posttreatment period. Hence, we do not include in our analysis specifications which include product-specific time trends.
} 


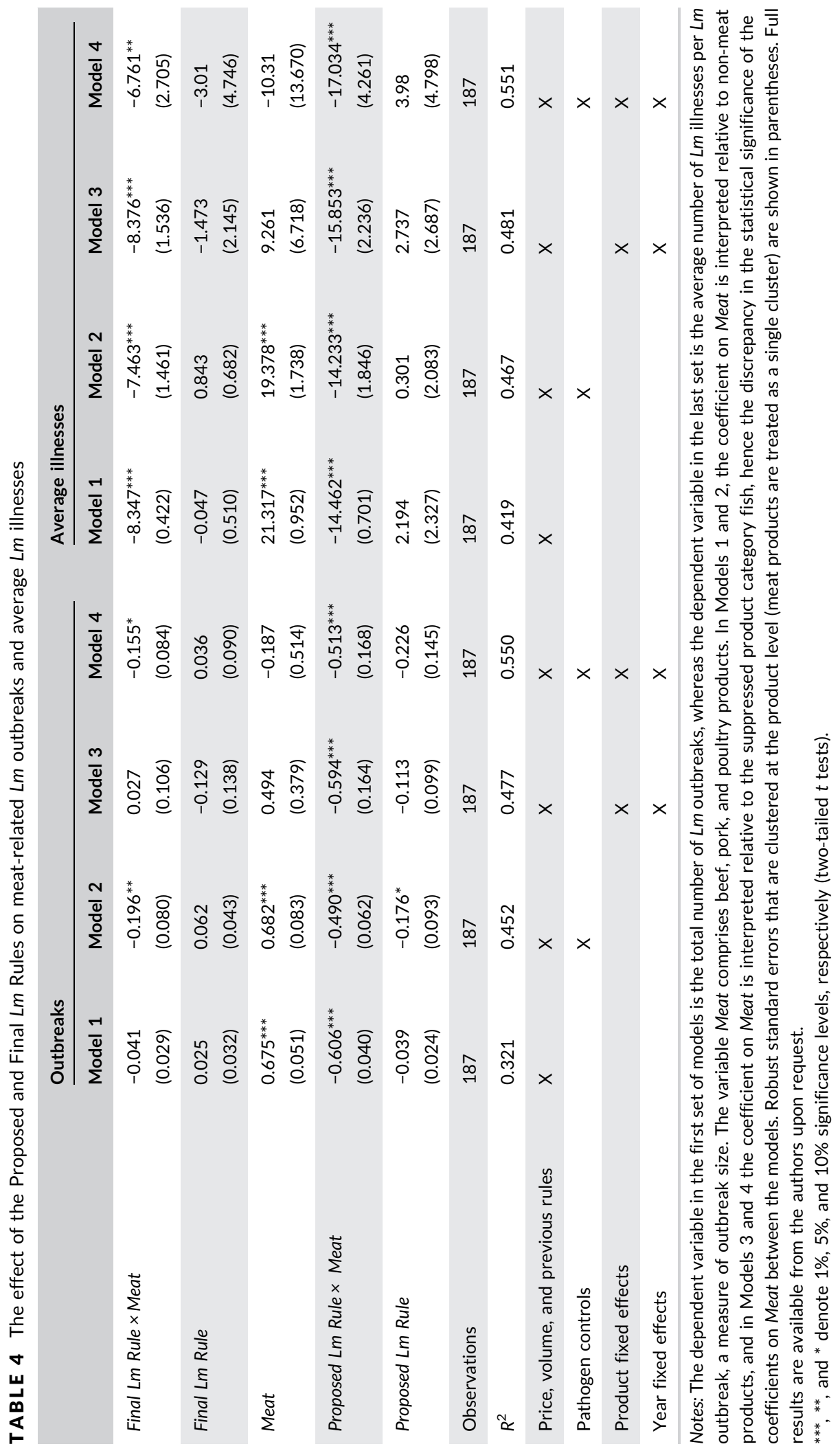


the overall number of meat-related Lm outbreaks as well as limiting the average size and scope of a meat-related $L m$ outbreak. Although we are unable to cite a specific mechanism underlying these reductions, it is likely that they are the result of a combination of safer production practices, as prescribed by the Proposed and Final Lm Rules, and less safe producers or products exiting the market. $^{16}$

Using the full model (Model 4) illness estimates presented in Table 3, we reevaluate the benefits of the Final Lm Rule originally estimated by the USDA in the FRIA. To do this, we begin with the estimated average annual reduction in meat-related $\mathrm{Lm}$ illnesses from Model 4 of $60(=37.5+22.2)$ and a combined underreporting and underdiagnosis multiplier of 2.3 , obtained from Scallan et al. (2011) ${ }^{17}$, the product of which yields approximately 138 meat-related Lm illnesses prevented annually by the Proposed and Final Lm Rules. Combining this with the mean cost of a Lm illness of $\$ 1.509$ million per illness (2016\$), obtained using the cost of foodborne illness estimates reported in Minor et al. (2015), produces an annual reevaluated benefit of approximately $\$ 208$ million (=138 $\times \$ 1.509$ million) $(2016 \$)^{18}$

The benefits estimated by the USDA in the FRIA are based on a historical risk assessment of $\mathrm{Lm}$ in deli meat products in which the USDA estimated that the Final $L m$ Rule would prevent meat-related $L m$ illnesses and deaths valued at approximately $\$ 176.7$ million per year $(2016 \$)$ in avoided related costs. Comparing our reevaluated benefits estimate with the USDA's benefits estimate, we note that the two estimates are similar in magnitude and exceed the $\$ 22$ million per year $(2016 \$$ ) cost to industry estimated by the USDA in the FRIA.

\section{6 | CONCLUSION}

Using 1998-2008 data collected by the CDC and compiled by Painter et al. (2013) on foodborne illnesses and outbreaks, we examined using a difference-in-differences approach the effect of the Proposed and Final $L m$ Rules on the number of meat-related $L m$ illnesses. This paper fills a gap in the food safety standards literature by being the first to our knowledge to examine the impact of the Proposed and Final Lm Rules on the number of meatrelated $L m$ illnesses and may help to inform the efficacy of similar food safety rules moving forward. We find that these rules together reduced the number of $L m$ illnesses associated with meat products by approximately 60 illnesses per year, resulting in a cost savings of about \$208 million per year (2016\$). From a policy perspective, that the annual cost savings associated with these rules compare favorably to the estimated annual cost of these rules of roughly $\$ 22$ million (2016\$) lends credence to them, and perhaps more generally to similar rules.

There are numerous advantages associated with the data used in this analysis, such as rigorous national collection techniques and pathogen-food pairings which make this type of analysis possible (Painter et al., 2013).

\footnotetext{
${ }^{16}$ Using U.S. Census Bureau Statistics of U.S. Businesses data, we did a pre-rules (1998-2003) and post-rules (2004-2008) comparison of the populationweighted average number of firms and employees belonging to North American Industry Classification System (NAICS) code 3116 (Animal Slaughtering and Processing), which revealed a roughly $11 \%$ post-rule drop in the average number of firms ( $p=.004$, two-tailed $t$ test) and an approximate $4 \%$ post-rule fall in the average number of employees ( $p=.006$, two-tailed $t$ test). Using, instead, 1998-2000 as the pre-rules period and 2001-2008 as the post-rules period revealed similar findings-a roughly $12 \%$ post-rule drop in the average number of firms ( $p=.002$, two-tailed $t$ test) and an approximate $3 \%$ postrule fall in the average number of employees ( $p=.050$, two-tailed $t$ test).

${ }^{17}$ As stated previously, the data used in this paper are based on state, local, and territorial health department reports of foodborne illnesses to the CDC (passive surveillance data). However, due to underreporting (some foodborne illnesses never get reported to public health authorities) and underdiagnosis (many people are never officially diagnosed with a foodborne illness), such reports typically capture just a fraction of the actual number of foodborne illnesses. The multipliers estimated by Scallan et al. (2011) are used to correct for this. More specifically, Scallan et al. (2011) report a Lm underreporting multiplier of 1.1, which suggests a rate of underreporting of $L m$ illnesses of 10 percent, and an $L m$ underdiagnosis multiplier of 2.1 , which suggests a rate of underdiagnosis of $\mathrm{Lm}$ illnesses of 110 percent. The resulting combined $\mathrm{Lm}$ underreporting/underdiagnosis multiplier is $2.3(=1.1 \times 2.1)$ and is comparatively low due to the relatively severe nature of a $\mathrm{Lm}$ illness and, thus, a high probability of such an illness being both reported and diagnosed.

${ }^{18}$ Given the large number of observations in our data set in which Lm illnesses are zero, as a robustness check we estimated Tobit models, but were only able to achieve model convergence for Models 1-3, and not Model 4. Averaged over Models 1-3, the Tobit estimates reveal that the two rules taken together reduced the number of meat-related $L m$ illnesses by about 36 illnesses per year which, when monetized, amounts to about $\$ 125$ million per year and that this illness reduction can be attributed to both a reduction in the number of meat-related $\mathrm{Lm}$ outbreaks as well as a reduction in the average size of a meat-related Lm outbreak, all of which is consistent with our findings presented in Tables 3 and 4 and discussed here.
} 
The data and analysis, though, are not without their limitations. First, the data are compiled and presented at the annual level, but the timing of the Proposed and Final Lm Rules occurs at the monthly level, as the rules were published in February 2001 and June 2003, respectively. This could potentially result in our estimated effects of the Proposed and Final Lm Rules being biased, although the likely direction of bias is unclear. Second, the data are compiled and presented at a national level. This prevents the inclusion of any regional factors that may have influenced growing or manufacturing conditions, which could also be factors contributing to an outbreak. Third, the point of contamination of the product is rarely discovered and not disclosed in the data. This prevents the analysis from controlling for farm, manufacturing, transport, or home use as the primary cause of illness, all of which could influence the size or scope of an outbreak.

\section{ACKNOWLEDGMENTS}

The views expressed here are those of the authors and may not be attributed to the United States Department of Agriculture, the Food and Drug Administration, or Johns Hopkins University. We would like to thank participants at the 2019 Food Safety Regulatory Economics Working Group 3rd Technical Meeting, the 2018 Agricultural and Applied Economics Association Annual Meetings, and the 2017 Society for Risk Analysis Annual Meetings, as well as the Editor and two anonymous referees, for helpful comments and suggestions that greatly improved the paper.

The usual caveat applies.

\section{ORCID}

Matt Parrett (iD http://orcid.org/0000-0003-0589-2207

\section{REFERENCES}

Amoa-Awua, W., Ngunjiri, P., Anlobe, J., Kpodo, K., Halm, M., Hayford, A., \& Jakobsen, M. (2007). The effect of applying GMP and HACCP to traditional food processing at a semi-commercial Kenkey production plant in Ghana. Food Control, 18, 1449-1457.

Angrist, J., \& Pischke, J.-S. (2009). Mostly harmless econometrics: An empiricist's companion. Princeton, NJ: Princeton University Press.

Asfaw, S., Mithofer, D., \& Waibel, H. (2010). Agrifood supply chain, private-sector standards, and farmers' health: Evidence from Kenya. Agricultural Economics, 41, 251-263.

Cenci-Goga, B., Ortenzi, R., Bartocci, E., Codega de Oliveira, A., Clementi, F., \& Vizzani, A. (2005). Effect of the implementation of HACCP on the microbiological quality of meals at a University restaurant. Foodborne Pathogens and Disease, 2, 138-145.

Centers for Disease Control and Prevention. (2016). Listeria (Listeriosis). Retrieved from https://www.cdc.gov/listeria/

Centers for Disease Control and Prevention. (2017). Listeria (Listeriosis) Symptoms. Retrieved from https://www.cdc.gov/ listeria/symptoms.html

Hong, C., Todd, E., \& Bahk, G. (2008). Aerobic plate counts as a measure of hazard analysis critical control point effectiveness in a pork processing plant. Journal of Food Protection, 71, 1248-1252.

Minor, T., Lasher, A., Klontz, K., Brown, B., Nardinelli, C., \& Zorn, D. (2015). The per case and total annual costs of foodborne illness in the United States. Risk Analysis, 35, 1125-1139.

Minor, T., \& Parrett, M. (2016). A retrospective review of the economic impact of the Food and Drug Administration's Proposed Egg Rule. Agricultural Economics, 47, 457-464.

Minor, T., \& Parrett, M. (2017). The economic impact of the Food and Drug Administration's Final Juice HACCP Rule. Food Policy, 68, 206-213.

Nada, S., Ilija, D., Igor, T., Jelena, M., \& Ruzica, G. (2012). Implication of food safety measures on microbiological quality of raw and pasteurized milk. Food Control, 25, 728-731.

Okello, J., \& Swinton, S. (2010). From circle of poison to circle of virtue: Pesticides, export standards, and Kenya's green bean farmers. Journal of Agricultural Economics, 61, 209-224.

Painter, J., Hoekstra, R., Ayers, T., Tauxe, R., Braden, C., Angulo, F., \& Griffin, P. (2013). Attribution of foodborne illnesses, hospitalizations, and deaths to food commodities by using outbreak data, United States, 1998-2008. Emerging Infectious Diseases, 19, 407-415.

Scallan, E., Hoekstra, R., Angulo, F., Tauxe, R., Widdowson, M., Roy, S., ... Griffin, P. (2011). Foodborne illness acquired in the United States-Major pathogens. Emerging Infectious Diseases, 17, 7-15. 
Soriano, J., Rico, H., Molto, J., \& Manes, J. (2002). Effect of introduction of HACCP on the microbiological quality of some restaurant meals. Food Control, 13, 253-261.

Strom, S. (2012). McDonald's menu to post calorie data. The New York Times. Retrieved from https://www.nytimes.com/ 2012/09/13/business/mcdonalds-to-start-posting-calorie-counts.html

Thrasher, M. (2013). Starbucks will start posting calorie counts at stores nationwide. Business Insider. Retrieved from https://www.businessinsider.com/starbucks-will-post-calories-nationwide-2013-6

United States Department of Agriculture (1996). Performance pathogen reduction: Hazard analysis and critical control point (HACCP), Federal Register (pp. 38805-38989). Washington, DC: United States Government Publishing Office.

United States Department of Agriculture (1999). Performance standards for the production of certain meat and poultry products, Federal Register (pp. 732-749). Washington, DC: United States Government Publishing Office.

United States Department of Agriculture (2001). Performance standards for the production of processed meat and poultry products, Federal Register (pp. 12590-12636). Washington, DC: United States Government Publishing Office.

United States Department of Agriculture (2003). Control of Listeria monocytogenes in ready-to-eat meat and poultry products, Federal Register (pp. 34208-34254). Washington, DC: United States Government Publishing Office.

Vojdani, J., Beuchat, L., \& Tauxe, R. (2008). Juice-associated outbreaks of human illness in the United States, 1995 through 2005. Journal of Food Protection, 71, 356-364.

Wang, D., Wu, H., Hu, X., Yang, M., Yao, P., Ying, C., ... Liu, L. (2010). Application of hazard analysis critical control points (HACCP) system to vacuum-packed sauced pork in Chinese food corporations. Food Control, 21, 584-591.

\section{AUTHOR BIOGRAPHIES}

Travis Minor received his Ph.D. in Economics from Middle Tennessee State University in 2009 and is a Senior Policy Advisor at the U.S. Food and Drug Administration's Center for Food Safety and Applied Nutrition located at 5001 Campus Drive, College Park, MD 20740. His current research focuses on the economics of food, including food safety systems, food loss and waste, consumer health outcomes, and policy analysis. Travis can be reached at Travis.Minor@fda.hhs.gov.

Matt Parrett received his Ph.D. in Economics from Virginia Tech in 2003 and is the Director of the M.S. in Applied Economics program at Johns Hopkins University located at 1717 Massachusetts Avenue NW, Washington, DC 20036. His research interests include food economics, behavioral economics, and labor economics. Matt can be reached at mbparrett@gmail.com.

How to cite this article: Minor T, Parrett M. An evaluation of the USDA's policy to reduce listeria illnesses in ready-to-eat meat and poultry products. Agribusiness. 2020;36:347-362. https://doi.org/10.1002/agr.21642 


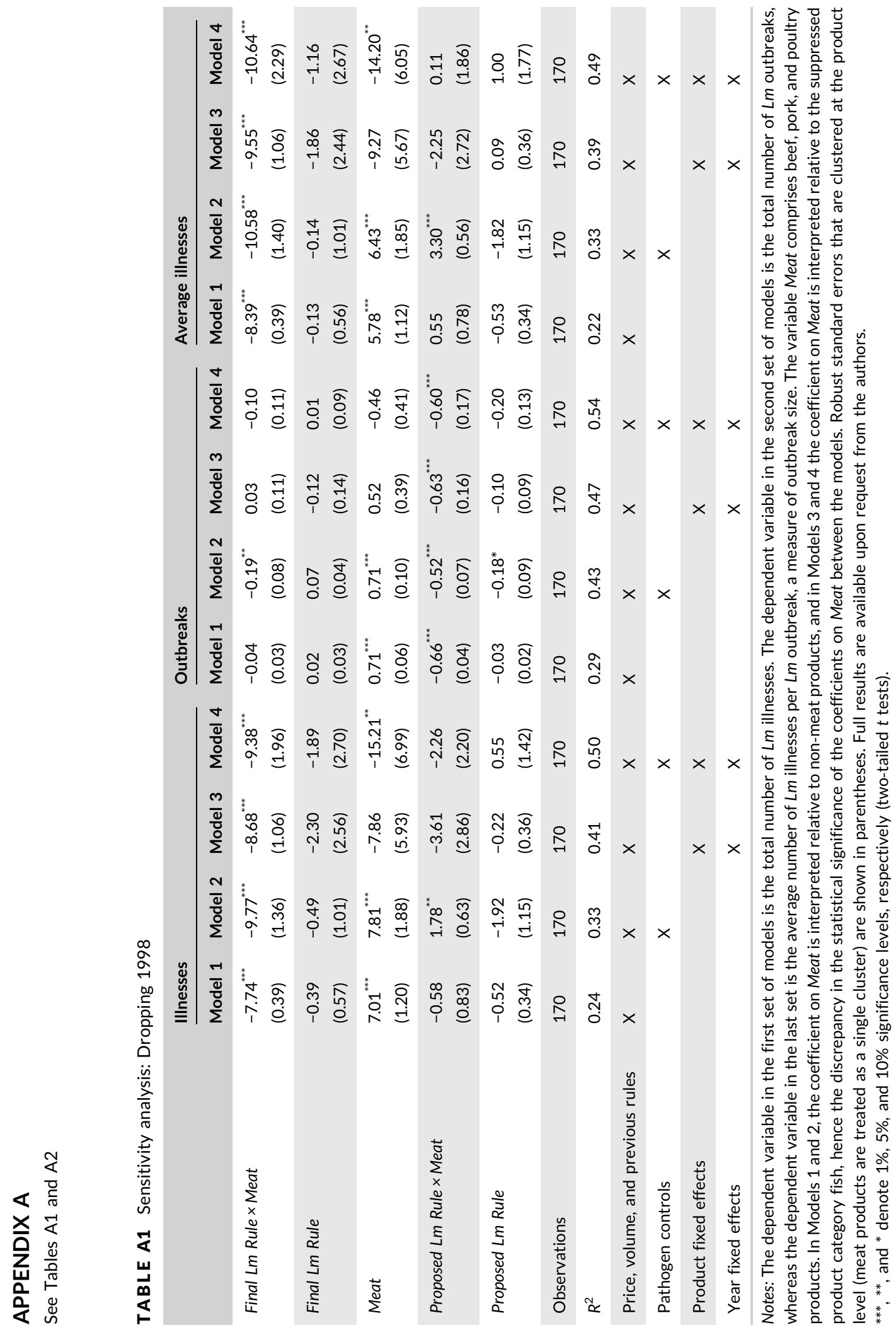




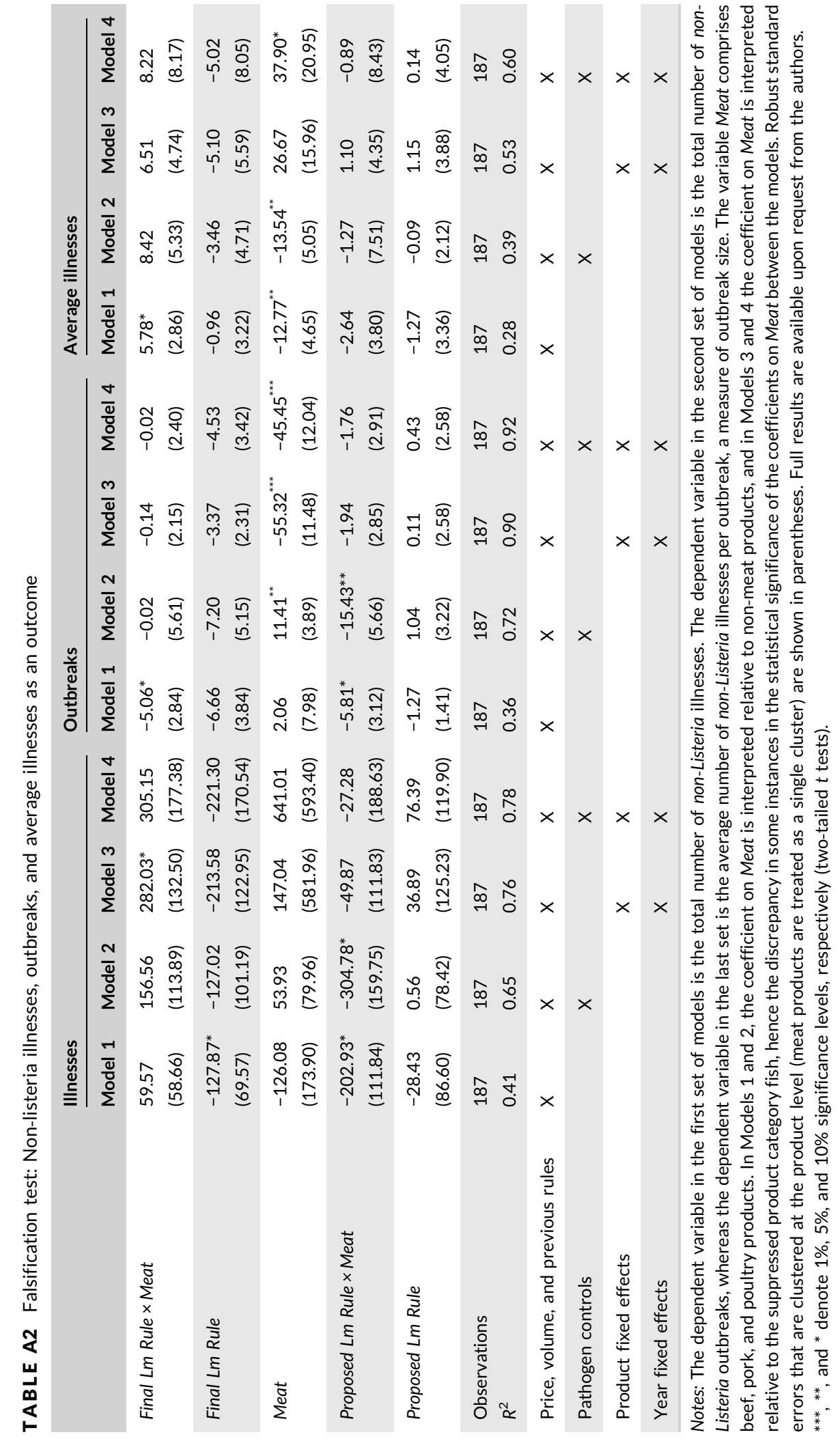

